\title{
National Learning (Guoxue): Six Perspectives and Six Definitions
}

\section{Liu Dong}

Translator. Guannan Li

\section{Q OpenEdition \\ Journals}

\section{Electronic version}

URL: http://journals.openedition.org/chinaperspectives/5380

DOI: 10.4000/chinaperspectives.5380

ISSN: 1996-4617

\section{Publisher}

Centre d'étude français sur la Chine contemporaine

\section{Printed version}

Date of publication: 1 January 2011

Number of pages: $46-54$

ISSN: 2070-3449

\section{Electronic reference}

Liu Dong, « National Learning (Guoxue): Six Perspectives and Six Definitions », China Perspectives [Online], 2011/1 | 2011, Online since 30 March 2014, connection on 28 October 2019. URL : http:// journals.openedition.org/chinaperspectives/5380; DOI : 10.4000/chinaperspectives.5380

(c) All rights reserved 


\section{National Learning (Guoxue):}

\section{Six Perspectives and Six Definitions}

\section{LIU DONG*}

\section{Guoxue deserves "such popularity"}

Let us first review how guoxue has "occurred" by citing an observation from a scholar who lives outside of China.

The concept of "guoxue," which ceased to draw attention for more than four decades, was resuscitated almost overnight in mainland China in the so-called "guoxue fever" of the 1990s... A variety of forums appeared on TV; several prestigious universities established guoxue training classes in order to nourish "spiritual resources" among management personnel; some local governments even organised the movement for elementary students to read the "Four Books" and the "Five Classics."(1)

A Il around us praise and denunciation of "guoxue fever" can be heard in heated debates. Twenty years ago, during the period of "guoxue chill," I pointed out, "Even those who do not know very much about tradition argue that China's current cultural crisis may be attributed to tradition or to its loss." (2) It is in this context of controversy that I invited an old friend of mine, Arif Dirlik, to the Tsinghua Academy of Chinese Learning (Tsinghua guoxue yanjiu yuan) to give a series of talks as Liang Qichao Memorial Visiting Professor. Within a general framework of global modernity, Dirlik offered an argument from his article entitled "Confucius in the Borderlands: Globalization, The Developmental State and the Resurrection of a Confucian Identity." Dirlik argues that Confucianism has been held responsible for both the success and the failure of China's modernity. Although I agree with Dirlik's argument on the intricate relationship between the revival of cultural values and the takeoff of the economy, I think there is no causal relationship between the promotion of Confucianist discourses and the flourishing of profit-making activities in China. In contrast to Xiong Shili, Liang Shuming, Feng Youlan, Mou Zongsan, Tang Junyi, and their intellectual descendants, the Confucian tradition actually offered moral normative values to challenge Western-originated modernity.

In fact, as China is on the verge of achieving the material promise of the "four modernisations," the negative effects of modernisation are becoming apparent, accompanied by a realisation that we cannot simply blame tradition for our problems. This calls for a distinction between the old "culture fever" (wenhua re) and the new "guoxue fever." While the former was deployed two decades ago to express a Chinese thirst for modernity, the latter, which brought new attention to tradition, has derived from a sober reflection on modernity.

In disagreement with Dirlik's observation, I also want to point out the popular and spontaneous nature of the new "guoxue fever." Unlike the pre- vious "fever" trends, this cultural movement was not promoted from the top down, but from the bottom up. The public has pressed cultural demands for guoxue. This is the key characteristics of the new guoxue trend. Although Dirlik's view on the relationship between Confucianism and the economic rise of Asia is not well-balanced, he keenly captures the question of how the rise in the market was closely associated with the deployment of Confucian doctrines as a means of making profit. Indeed, in China, from universities to the Temple of Confucius, from book stores to private schools, from book writing to academic lectures, all are contaminated by money.

However, I insist even under such circumstances that continued destruction of tradition, particularly the Confucian tradition, will not help overcome China's moral anomie. Without the constraint of Confucianism, Yang-Zhu egoist philosophy ${ }^{(3)}$ could be re-activated by Western individualism and celebrated as "advanced theory" (xianjin xueshuo). (4) For this reason, although "guoxue fever" may not prevent profit-making activities at the current initial stage, I still have a faith that the inherent value system of Chinese culture remains the most vital and effective means to regulate public moral life and enrich the Chinese historical experience. For this reason, I believe in the unique and positive impact of "guoxue fever" on China's future.

Based on this faith, I have no hesitation asserting that if Chinese civilisation is to survive, Chinese tradition deserves to be popularised and traditional guoxue, especially Ruxue, must reach even greater constituencies. Of course, I do not intend to ignore many current pressing problems. On the one hand, we are still debating the intricate relationships among "culture," "tradition," "guoxue," and "Ruxue." We even need to clarify what guoxue fever is about. On the other hand, I have experienced many fever trends in my life, such as "aesthetics fever" (meixue re) in the 1980s and the later "culture fever." I am quite wary of the alienation and desperation that follow temporary fevers lacking a foundation in rationality.

Dr. Liu Dong is Distinguished Professor of Aesthetics, Comparative Literature \& Sinology, and Vice Dean of The Tsinghua Academy of Chinese Learning, Tsinghua University.

1. Yu Yingshi, "The Concept of 'Guoxue' and Chinese Humanities Studies," the keynote speech of the 28th meeting of Academicians of Academia Sinica, 1 July 2008, in He Jun (ed.), Yu Yingshi xueshu sixiang wenxuan (The Article Collection of Yu Yingshi's Academic Thinking), Shanghai, Shanghai guji chubanshe, 2010, p. 433.

2. Liu Dong, "Huidao zhouxin shidai" (Return to the Axis Age) in Liu Dong (ed.), Zhonghua wenming duben (Chinese civilisation: A reader), Nanjing, Yilin chubanshe, 2009, p. 1.

3. Yang Zhu, a Chinese philosopher during the Warring State (475-221 BCE), advocated the primacy of self-preservation. His famous statement, "Mankind is surely not to be helped by a single hair." (Ba yi mo er li tianxia, bu wei ye), is regarded as extreme egoism.

4. See Liu Dong, "Shiqu rujia zhiheng de 'gerenzhuyi:' Zhou Zuoren anli yanjiu" ("Individualism" without Confucian restriction: The case study of Zhou Zuoren), in Liu Dong, Lilun yu xinzhi (Theory and mind), Nanjing, Jiangsu renmin chubanshe, 2001, pp. 88-114. 
Facing these uncertainties, we should ponder especially the validity of the concept of guoxue. Ma Yifu observes, "Nowadays people use this concept - guoxue... Usually, guoxue means national universities (guoli daxue). Now people use it to refer to China's inherent learning in order to distinguish it from foreign learning... This designation is too broad, which makes people wonder what kind of learning it specifically refers to." (5) As Cai Shangsi pointed it out in 1932, the meaning of guoxue varied based on different interpretations. "For scholars, some think guoxue refers to the essence of Chinese thinking (Cao Juren), some think guoxue is the linguistic study of Chinese language (Wu Wenqi), others deploy a historical perspective to understand it (such as Zhang Xuecheng and Zhang Taiyan), and many people even misunderstand it as Chinese writing (guowen)." (6)

Over a century of (re)thinking, the meaning of guoxue has changed and shifted with changes in the problems and concerns that have called it forth. The goal of this article is to explore the diverse meanings that have been invented and injected into these two characters. The amount of ink spilled on "guoxue" from the late Qing through the Republic gives us more than enough material to justify the discussion below.

\section{Self-restriction in the face of the cultural Other}

Professor Li Ling has ridiculed guoxue: "Although guoxue seeks to distinguish itself from Western learning, it is actually the learning that is going to extinguish our nation (guo jiang buguo zhi xue)." (7) The literature on guoxue is replete with this concern. In 1935, ten professors, including Wang Xinming, asserted:

China has culturally vanished because China has lost the [traditional] characteristics of her political system, social organisation, and intellectual substance. The people, who are fostered by this characterless politics, society, and spirit, are gradually becoming non-Chinese. We can assert that from a cultural perspective, there is no place for China in the modern world. Within China's territory, there are almost no [true] Chinese people." (8)

Wang's statement introduces my first perspective on guoxue. Guoxue appeared in a critical situation when the nation was in great peril. The neologism guoxue was introduced from Japanese, but the problematic associated with the term was indeed indigenous. It expressed a self-restricted definition of indigenous learning in forced acknowledgment of a powerful cultural "Other" in a context of Western oppression.

For the literati and scholars in the late Qing, guoxue as a defensive strategy first meant self-depreciation because they were forced to render old Chinese universal values into regional or nation-based learning. Consequently, the character of guo in guoxue did not refer to the magnificent and alluring empire any more, but at best indicated the competing nationstate that fell into the general framework of the modern world. Under this premise, people brought forward "the national character" (guoxing) to support guoxue. For instance, early in 1916, Zhou Jiebi already used nationstate to designate the nature of a certain culture. Zhou's concept was largely different from that of Arthur Henderson Smith and Lu Xun, who defined and popularised "the national character" (guominxing) as the "wicked root" (liegen xing) of the nation-state. As Zhou claimed, "Every nation relies on national character to establish itself. The national character is the national spirit. Its manifestation in the national history, politics and religion, folklore, custom, and language is called guoxue." (9) In a similar fashion, Gu Shi enumerated neologisms such as "national writing" (guowen), "national language" (guoyu), "national music" (guoyue), "national skills" (guoji), "national essence" (guocui), "national tradition" (guogu), and "national goods" (guohuo) and regarded them as the means to withstand the invasion of the foreign material civilisation. In this context, "guoxue was accordingly born." (10)

Debates over the true meaning of guoxue in the late Qing did not deny or reject Western learning. What they could not agree on was acknowledging the universalism of Western learning and the appropriate scale of its introduction. Guoxue was regarded by many as undesirable because the preservation and promotion of a learning tradition would inevitably restrict and oppose "wholesale westernisation." In 1908, an article entitled "Oppose" (fan) appeared in a journal published by Chinese students in Paris. Attacking "the national essence" as useless, this article proposed to "put the national essence into the museum." As the author remarked.

If we continue to praise the ancient and blame the present, honour ourselves and denounce others, and distinguish ourselves from others, it could lead to rigid confirmation of national boundaries and finally cause men's degeneration. Science is beyond national boundaries. Knowledge resides in all nations. Learning makes no distinction between East and West or the white and the yellow race. (11)

This view reminds us of Joseph Levenson's later argument about the "museum." This type of cultural nihilism probably could only originate from those who lived abroad during the late Qing, when museums were still foreign to China.

This stance of cultural radicalism was also reflected in Zhou Zuoren's thinking. As Zhou argued, "I believe that only the good and still existing national essence is worth preserving and can be preserved... From my perspective, except for the restoration of the old and the repulsion of the foreign (fugu paiwai), Chinese national character has nothing worth preserving." (12) Even though the Zhou brothers were experts on guoxue, they defamed traditional culture, and deep in their hearts could find no grounds for preserving Chinese culture.

More critically, this kind of cultural radicalism was not only manifested in literary circles, but also spread to political circles. As Chen Duxiu declared in 1918 in the New Youth Journal:

5. Ma Yifu, "Taihe huiyu" (Conversations in Taihe), in Ma Yifu, Ma Yifu ji (The collection of Ma Yifu), Hangzhou, Zhejiang guji and Zhejiang jiaoyu chubanshe, 1996, p. 9.

6. Cai Shangsi, "Guoxue zhi dingyi ji fenlei" (Definition and categorisation of guoxue), in Cai Shangsi, Zhongguo xueshu dagang (The outlines of Chinese learning), Shanghai, Shanghai qizhi shuju, 1932, p. 5.

7. Li Ling, "Chuantong weishenme zheyang hong: ershinian mudu zhi guaixianzhuang" (Why tradition is so popular: Strange events seen over 20 years), in Li Ling, Fanghu guishan (Let the tiger back to the mountain), Taiyuan, Shanxi renmin chupanshe, 2008, p. 227

8. Wang Xinming, "Zhongguo benwei de wenhua jianshe xuanyan" (The manifesto of China-grounded cultural construction), Wenhua jianshe (Cultural Construction), vol. 1, no. 4, 10 January 1935.

9. Zhou Jiebi, "Xuesheng yi zunzhong guoxue"(Students need to respect national learning), Xuesheng zazhi, no. 3, 1916.

10. Gu Shi, Preface to Guoxue yanjiuhui yanjianglu xu (The collection of lectures at the Society of National Learning Studies), Shanghai, Shangwu yinshuguan, 1923, p. 4.

11. "Fan" (Opposing), Xinshiji, no. 44, Paris, 25 April 1908.

12. Zhou Zuoren, "Luosu yu guocui" (Russell and national rssence), Chenbao fukan (Supplement of Morning News), 19 October 1920 
Chinese learning's flourishing in the Eastern Zhou was nearly comparable to that of ancient Greece in Europe. However, while European learning has advanced since the time of the Greeks, Chinese learning has declined since the Eastern Zhou. Of course, we can sift sand for the gold of ancient Chinese learning, but contemporary European learning has also thrived and has far exceeded its ancient achievement. If we want gold, why should we go back to the distant Chinese past when European learning is even closer?"(13)

Note that this article was written only three years before the establishment of the Chinese Communist Party.

Moreover, such views were not limited to Communists. China's Nationalists shared with the Communists a similar view that aimed to transform "East-West conflicts" (zhongxi zhi zheng) into "ancient-present differences" (gujin zhibie). As Wu Zhihui remarked,

What is national tradition? It is just an antique that needs to be preserved. Letters from Egypt and Babylon, learning from Greece and Rome, Buddhist sutras, and China studies from Zhou, Qin, Han, and Wei are all things for the public to preserve in the world. National institutes from different countries should select their best scholars to study and organise these antiques. But how can we use them to educate our youth in the contemporary world? (14)

In fact, brought forward with reference to the powerful cultural other, this self-restricted concept of guoxue aimed to achieve some balance between China and the outside world. Contemporary scholars used "subsidiary awareness" or "essential tension" to conceptualise the problems China faced. Scholars such as Liang Qichao, the leader of the reform movement, apparently realised that if a centripetal identity and pride in Chinese culture could not be maintained, and Chinese identity was allowed to diminish little by little, there would be no need to talk about "the salvation of our country and the preservation of our race" (jiuwang baozhong). For this reason, while history could not go back to the "stone age" to start again, we must make our best efforts in the present to fight against the decline of social collectivity by maintaining a positive interaction and a critical dialectics between "the transformation of the new" (gexin) and "the preservation of the old" (shoujiu).

A sense of the need to preserve Chinese identity was not limited to Liang Qichao, but was shared by all those who advocated guoxue, including high officials of the Qing, scholars from the Tongmenghui, and numerous other known and unknown figures. For instance, Zhang Shizhao wrote in 1906, "Guoxue is the original resource to establish our country. In a world of competition, I haven't heard of the establishment of a country without the flourishing of guoxue, but l've heard about the preservation of guoxue after the demise of a country." (15) In a 1907 memorial, Zhang Zhidong wrote, "National writing includes our nation's writing, language, and books passed down from antiquity. We must preserve and transmit them... We must cherish our specialised learning, skills, and ethos. We call them the national essence. They are the foundations of the Western and Eastern great powers. We cannot ignore them." (16)

More crucially, we must replace the concept of "old and new" grounded in temporal teleology with the spatial, changing, and incidental concept of "China and the West." In doing so, we can overcome the Darwinian principle of "the survival of the fittest" in a world history dominated by the blowing Western wind. This not only provided the opportunity for cultural adjustment and compromise in the late Qing, but also created an intellectual foundation for contemporary cultural selection and transplantation.

\section{An active response to foreign learning}

Let us start with Zhang Zhidong's famous statement_- "Chinese learning for substance and Western learning for function." I have been thinking about this question for a long time: what on earth is wrong with this idea? In a recent conversation with a journalist, I commented,

So-called "Western Civilisation" is itself heterogeneous and even divided. Similar and complementary to Chinese civilisation, Greek civilisation was not only rational and critical, but also practical, aesthetic, secular, and positive. Only for some incidental reasons did scientific culture and democratic institutions develop out of the Greek civilisation. For this reason, I have been thinking to reinterpret and reactivate the concept of "Chinese learning for substance and Western learning for function." If our collective community can be established on the inter-subjectivity between "Chinese and Greek civilisation," then we can preserve our rich traditional cultural resources, maintain individual morality and mind, and at the same time adopt the democratic institutions introduced from Greece to adjust our social relationship. What a harmonious and vital prospect! ${ }^{(17)}$

After long reflection, I have gradually reached the conclusion that for a long time people have misunderstood the idea of "Chinese essence and Western function" (zhongti xiyong). In fact, this cultural creed was the key to the success of the early Tsinghua Academy of Chinese Learning!

From a historical perspective, "Chinese essence and Western function," which put "China and the West" on an equal plane, was indeed a very open attitude for its time. As Wang Guowei argued in 1911, "In the current world, I believe that Chinese learning could not flourish without Western learning, and Western learning could not flourish without Chinese learning." (18) In 1920, Lu Dajie brought forward a similar notion: "At this moment of global interaction, the world will merge into one... It will be impossible to conduct a study without a global perspective... This global vision will revive our guoxue." (19) Under the influence of this open attitude, Western learning was gradually accepted among Chinese scholars, paving the road for the success of the Tsinghua Academy of Chinese Learning.

Significantly, the four mentors (Liang Qichao, Wang Guowei, Chen Yinque, and Zhao Yuanren, or the five mentors if including $\mathrm{Li}$ Ji) in the Ts-

13. Chen Duxiu,"Suiganlu"(Random thoughts), Xinqingnian, no. 4, April 1918.

14. Wu Zhihui, "Zhen yangbagu hua zhi lixue" (On the science of the Western eight-legged essay), Chenbao fukan, 27 March 1923.

15. Zhang Shizhao, "Cuoxue jiangxihui xu" (Preface to the Society of National Learning Seminars), Minbao, no. 7, September 1906.

16. Zhang Zhidong, "Chuangli cungu xuetang zhe" (Memorial on the establishment of the school of preserving the old), in Zhang Zhidong quanji (The complete works of Zhang Zhidong), Shijiazhuang, Hebei renmin chubanshe, vol. 3, p. 1762.

17. Liu Dong, "Guanyu dangdai jingshen kunjing de dawen" (Interview on the contemporary predicament of mind), Xinzhoukan, 15 August 2010, pp. 62-63.

18. Wang Guowei, "Guoxue congkan xu" (Preface to the National Learning Series), in Wang Guowei, Wang Guowei yishu, Shanghai, Shangwu yinshuguan, 1940.

19. Lu Dajie, "Lun jinri zhiguo xuezhe suo ying gailiang zhi shida fangzhen" (On ten principles to improve today's scholars), Weishi, no. 2, May 1920. 
inghua Academy of Chinese Learning all had backgrounds in foreign learning. "They were Chinese scholars who were versed in Western learning. Their global framework provided them with a new perspective to reflect upon indigenous learning and culture." (20)

Under the guidance of these pioneers, teachers and students from the Tsinghua Academy of Chinese Learning and other scholars from its outer circle maintained a positive and active attitude toward foreign learning, even though they made it clear that their specialty was guoxue. When the Institute was established, Wu Mi suggested a synthetic principle for conducting guoxue: "So-called guoxue refers to the totality of Chinese learning and culture. Its analytical approaches must rely on correct and precise means (the so-called scientific means)." (21) In a similar fashion, Zheng Zhenduo wrote, "When we examine ancient books and philosophy, literature from the middle ages, and modern history, we must have some basic foreign knowledge and consult books written in foreign languages." (22)

While the faculty in the early Tsinghua Academy of Chinese Learning and other like-minded people all emphasised Western learning as the foundation of knowledge, they did not want to blindly follow Western learning because in their hearts there existed traditional resources from which they drew their intellectual strength. They firmly believed that the precondition for the large-scale introduction of Western learning for the purpose of cultural hybridisation was the construction of a strong Chinese body and mind. As Song Shu had written early in 1905, "If our national essence is weak, then it will be impossible to introduce other foreign essences; if our national essence flourishes, it will become natural to make connections between Chinese and foreign essences." (23)

In order to develop their capability to introduce and accept Western learning, this open academic mind represented by the Tsinghua Academy of Chinese Learning inevitably required a sympathetic and respectful attitude toward the indigenous cultural tradition. They believed that their commitment to Chinese culture would generate long-term vitality to confront the invasion of Western learning. Early in 1904, Liang Qichao already had reached such a conclusion when he stated, "When they see new scholars abandoning guoxue, some contemporary pessimists are afraid of the demise of guoxue. However, I'm not afraid at all. I'm certain that the introduction of foreign learning will indirectly lead to the vitality of guoxue." (24) Consequently, the tendency of the Tsinghua Academy of Chinese Learning was not to "preserve the old," but rather was involved with an extremely active attitude toward "initiating the new" (kaixin). More importantly, this cultural creed of "Chinese learning for substance and Western learning for function" not only intended to represent the indigenous value system, but also sought to deploy the integrated experiences of Chinese civilisation to actively respond to newly introduced Western models, and took this as an opportunity to obtain access to modern civilisation.

There is a second perspective on guoxue. The concept of guoxue, which referred to inherited Chinese learning and culture, and synthesised thousands of years of experience, was an active response to the formidable challenges posed by modern Western learning. In this sense, viewed dialectically, once introduced into China, Western learning could be transformed into "semi-guoxue" or "guoxue," and thus break down the conventional boundary between "guoxue" and "Western learning."

Through this means, Chinese tradition, which was judged by some to be decadent and useless, instead exhibited its openness for active remoulding and selection. Accordingly, the meaning of tradition became more flexible, fluid, and incorporative. This dialectical relationship between "retrospec- tion" (huaijiu) and "the future" (weilai) was thus beyond either activism or nihilism. As Huang Jie commented on the vitality and flexibility of guoxue, "If the national essence is something we already have and is suitable for us, other things that are introduced from foreign countries and are equally applicable to China can also be called the national essence." Because of this attitude, Mao Zishui remarked that although it seemed that "national tradition" (guogu) was already dead, "Europeanisation" (ouhua) was the means to develop it. Therefore, the fate of guoxue, according to Zhang Xuan's comment on Mao Zishui, "relies on our attitude. If we give up and regard it as a dead thing, I then believe the national tradition is already dead. However, if we pursue unknown knowledge based on our existing learning, the national tradition will always be new and updated." (25)

From this perspective, we can now clarify some misunderstandings regarding the meanings of guoxue. For instance, in conferences we often hear people debating the content of guoxue. Some argue that guoxue should be limited to the "six classics" (liujing) or "six arts" (liuyi), while others believe guoxue should also include "the hundred schools of thought" (zhuzi baijia). This debate can be resolved from our new perspective of guoxue. The successful cases from the Tsinghua Academy of Chinese Learning demonstrate that Liang Qichao's new histories and new novels, Wang Guowei's aesthetics and comparative literature, Chen Yinque's oriental studies and frontier studies, Zhao Yuanren's linguistics, and Li ji's archaeology can be all called new guoxue because of their roots in Chinese culture.

Of course, this open attitude does not mean completely deconstructing Chinese tradition. As long as this kind of new learning remains in the category of guoxue, it will require a devout and respectful attitude to Ruxue as the core of Chinese learning. Otherwise, guoxue would be completely destroyed from its base.

\section{The general term for traditional learning and culture}

Under circumstances of strong Western influence and the collapse of old civilisational values in the early twentieth century, the core meaning of the Chinese historical experience became more and more difficult to define. The conflicts between the two reading lists I discuss below highlight the clashes between "literature" and "history," "thick" (hou) and "thin" (bo) experiences in guoxue, "academic research" (yanjiu) and "amateur interest" (hanyong), and "internal" and "external" learning.

In 1923, Hu Shi was invited to give a minimum guoxue reading list for young Tsinghua students who were going to study abroad. (26) However, after receiving Hu Shi's reading list, Tsinghua students were not satisfied,

20. Liu Dong, Preface to Qinghua daxue guoxue yanjiuyuan sida daoshi nianpu changbian xilie (The long collection of the biographical chronologies of the four mentors in the Tsinghua Institute of National Learning), Beijing, Zhonghua shuju, 2010, p. 1.

21. Wu Mi, "Qinghua kaiban yanjiuyuan zhi zhiqu ji jingguo" (The purposes and the process of the establishment of the Tsinghua Institute of National Learning), Qinghua zhoukan, no. 351, 18 September 1925.

22. Zheng Zhenduo, "Qie mantan suowei guoxue" (Let us talk about the so-called Guoxue), Xiaoshuo yuebao, vol. 21, no. 1, January 1929.

23. Song Shu, "Shangdongfu qingzou chuang cuihua xuetang yi" (Memorial on the establishment of Cuihua School), in Song Shu, Song Shu ji, Beijing, Zhonghua shuju, 1993, p. 373.

24. Liang Qichao, "Lun Zhongguo xueshu sixiang bianqian zhi dashi" (The great trend of the transformation of Chinese Learning), in Liang Qichao, Yinbingshi heji wenji, Beijing, Zhonghua shuju, 2003.

25. Zhang Xuan, "Bo xinchao guogu he kexue de jingshen pian" (Refute "The spirit of the national past and science" from the Journal of Xinchao), Guogu, no. 3, May 1919.

26. Hu Shi, "Yige zuidi xiandu de guoxue shumu" (A minimum book list of national learning), Dongfang zazhi, vol. 24, no. 4, 25 February 1923 
because Hu's list narrowly focused on literary and intellectual history When students turned to Liang Qichao, Liang offered another list that included books with a broader scope of moral cultivation, intellectual history, political history, philology, phonology, and grammar. Liang ridiculed Hu Shi's list as "a joke because it included Three Heroes and Five Gallants (Sanxia wuyi) and The Strange Cases of Nine Cases (Jiuming qiyuan), but excluded The Records of Grand Historian (Shiji), The Book of Han (Hanshu), and Comprehensive Mirror for Aid in Government (Zizhi tongjian)." (27) Clearly, although it is true that Hu focused more on "literary" studies and Liang paid more attention to "historical" studies, the deep difference between them is that Hu entered guoxue through "research" but Liang wanted to do "research" on guoxue because he was already into guoxue.

This difference indicates some fundamental conflicts between "external" and "internal" learning. By any standard, Hu Shi did not identify with Chinese cultural values. As Hu unsympathetically claimed, "Guoxue is an impasse. I find no treasure in national tradition." (28) For scientifically inclined scholars such as Hu Shi, (29) it was natural to deploy science as an external supporting pivot to make negative judgments on Chinese culture. As he argued, "The focus of 'reorganising national tradition' (zhengli guogu) is 'reorganising'... We propose to use an objective attitude and accurate scientific means to search for the clues of old cultural transformations in order to constitute partial or complete Chinese cultural history." (30)

Hu Shi never acknowledged the existence of guoxue, because guoxue, according to $\mathrm{Hu}$, must be rearranged by the external scientific principle. The movement to "Reorganise National Tradition" was thus naturally a movement of "deploying the West to measure China" (yixi gezhong), which used "science" from Western learning to rigidly rearrange the "humanities" in Chinese learning.

$\mathrm{Hu}$ Shi's ideas were very well received by the academic mainstream. Backed by institutional and funding support, Hu's ideas later became the official paradigm. The historical consequence was the deployment of "seven disciplines" to re-categorise the traditional "four treasures" and integrate indigenous guoxue into a semi-Western knowledge system. ${ }^{(31)}$ By doing so, the unity of traditional learning was broken and smashed, and the earlier categories were separately attached to the branches of the semiWestern knowledge system. Through "the order of things," Chinese indigenous learning was attacked and transformed by the dominant Western civilisation. Since then, even Chinese students who live in China could not receive the original guoxue education and were separated from their tradition.

Of course, some scholars who disagreed with Hu Shi regarded guoxue as a consistent system and suggested it as an alternative to the foreign knowledge system. For instance, in 1922, Shen Jianshi challenged Hu Shi face-to-face and argued that "although the Division of Guoxue (guoxuemen) at Peking University consists of Chinese literature, philosophy, and history, the scope of guoxue is much broader and is not limited to these three departments." (32) Following the traditional knowledge categorisation, Hu Pu'an in 1923 divided Chinese learning into six categories, including "1) philosophy, 2) ritual and religion, 3) history and geography, 4) language and letters, 5) writing, and 6) arts." (33) Unfortunately, at the time these voices were very weak and sounded "outdated."

More crucially, the key difference between Chinese and Western knowledge categorisation is their expectation of scholars. While Chinese learning aims to produce a cultural type that has the capability to "govern the country and establish peace in the world" (zhiguo pingtianxia), Western learning attempts to produce specialised academic experts in order to achieve knowledge reproduction and innovation. Although both systems categorise knowledge, the Chinese system requires the unity and integration of classics, history, philosophy, and miscellaneous collections. In contrast, Western categorisation emphasises disciplinary boundaries. Even though interdisciplinary interaction is often encouraged, cross-disciplinary emphasis mainly remains an individual interest and sometimes even invites the mockery of "not attending to one's own business" (buwu zhengye). Under the standard of this Western system, according to Zheng Zhenduo, guoxue was not even considered a special discipline. (34)

Sadly, under this new criterion of specialisation, traditional culture's ingenious demand for versatility was understood as the very reason to reject guoxue. As He Bingsong commented in 1929, "Guoxue is against the modern scientific spirit because it shows our reckless attitude toward learning. We Chinese always want to be comprehensive but instead end up knowing nothing. In contrast, the modern scientific spirit focuses on the division of labour and pays great attention to accurate analysis." (35)

During this process, we have learnt a bitter historical lesson: we felt so ready and eager to rearrange the Chinese knowledge system based on the Western framework even under conditions of limited understanding of the West. Gradually, the Chinese learning system was rendered even more Western and extreme than Western learning. As I describe this process in another article, "Our undergraduate education has become so extreme... If the knowledge composition in a traditional society commonly contains 30 percent specialised knowledge and 70 percent general knowledge, after the industrial revolution the percentage rate between these two kinds of knowledge in the West declined to 50-50 and later even reached 60-40... In China, the situation was even worse. Our knowledge composition rate between specialised and general knowledge declined to 70-30, 80-20, and even 90-10." (36)

Ironically, this cultural decline caused by the worship of the West in turn advocated versatility as the secret of Western learning. This idea simply ignored the fact that Chinese civilisation never lacked emphasis on versatility. As Qian Mu pointed out, "Since ancient times, China has developed specialised learning such as astronomy, computation, and medicine. Now all of them belong to the modern natural sciences. People will easily become absorbed in these kinds of learning without nourishing their humanity. While Chinese ancient tradition seems to neglect these areas of study,

27. Liang Qichao, "Guoxue rumenshu yaomu jiqi dufa" (The entry book list of national learning and its reading methods), Qinghua zhoukan, no. 281, May 1923.

28. "Yanjiusuo guoxuemen disici kenqinhui jishi jiexuan" (The selected report of the fourth grand reunion of the National Learning Department of Beijing University), Beijing daxue yanjiusuo guoxuemen yuekan, vol. 1, no. 1, October 1926.

29. See D. W. Y. Kwok, Scientism in Chinese Thought, 1900-1950, New Haven, Yale University Publishing Press, 1965.

30. "Yanjiusuo guoxuemen disici kenqinhui jishi jiexuan," op. cit.

31. See Zuo Yuhe, Cong sibu zhixue dao qike zhixue: xueshu fenke yu jindai zhongguo zhishi xitong zhi chuangjian (From the learning of four treasures to seven disciplines: Academic disciplines and the construction of the modern Chinese knowledge system), Shanghai, Shanghai shudian chubanshe, 2004.

32. "Yanjiusuo guoxuemen weiyuanhui diyici huiyi jishi" (The report of the first meeting of the committee of the National Learning Department of Beijing University), Beijing daxue rikan, no. 968, 27 February 1922

33. Hu Pu'an, "Yanjiu guoxue zhi fangfa" (The methods of studying national learning), Minguo ribao, 13 June 1923.

34. Zheng Zhenduo,"Qie mantan suowei guoxue," op. cit.

35. He Bingsong, "Lun suowei guoxue" (On the so-called National Learning), Xiaoshuo yuebao, vol. 21, no. 1, Jan. 1929.

36. Liu Dong, "Zhushen yu dongshi" (Gods and versatility), in Liu Dong, Daoshu yu tianxia, Beijing, Beijing daxue chubanshe, 2011, p. 402 
in reality it aims to correct this wrong tendency by preventing knowledge segmentation and division." (37)

There is still a third perspective on guoxue. Since the cultural clashes between China and the West, the idea of "deploying the West to measure China" constantly employed foreign concepts to divide inherited Chinese civilisation, which directly led to the chaos of the Chinese value system. As a response to the mechanical division of knowledge, in everyday use guoxue became the general designation for Chinese traditional learning with a vision to restore the comprehensiveness of traditional culture and the versatility of education.

In hindsight, if at the very beginning we had not blindly followed Western learning and had been content with a limited knowledge of the West, we probably could have developed a more prudent and balanced attitude. This painful historical lesson recalls the warning given by Lu Maode in 1942 concerning knowledge deficiency and intellectual imprisonment in Western learning: "Since the establishment of Republican China, scholars have suddenly advocated 'knowledge for knowledge's sake.' The popularity of this approach drove many of them to examine things but ignore their essence and associated function... This is not the orthodox way of doing guoxue... Therefore, after 30 years, versatile talents (quancai) have disappeared." (38) Consequently, regardless of our perspective in approaching guoxue, we should remember the advice given by Ma Yifu in 1938:

Any student who wants to study guoxue must be very clear about these ideas:

This learning is not disjointed, but contains a system. Do not take it as if they were groceries.

This learning is not old and rigid, but still alive and fresh. Do not regard it as antique.

This learning is not forcedly arranged, but is created naturally. Do not view it mechanically.

This learning is not the result of external factors, but is original and inherent. Do not think it is external. (39)

\section{Competition among Chinese studies}

To a great extent, guoxue studies were developed out of the inspiration and challenges posed by external Chinese studies. This external cultural stimulation, although sometimes negative, did introduce novel academic criteria, provided fresh perspectives, and created enthusiastic research interest for guoxue studies. For instance, Chen Yinque's frontier studies were inspired by the dominant international interest in Mongol Studies at the time. Zhao Yuanren's dialect studies continued and extended missionary reports on local languages. The rise of archaeological excavation and cultural preservation was somewhat stimulated by Aurel Stein and Paul Pelliot's cultural looting.

Moreover, at the moment when modern guoxue studies took its form, guoxue and Sinology (Hanxue) started to interact with each other. For instance, when Luo Zhenyu identified the scholars who interacted with Wang Guowei, we surprisingly discovered that many scholars within Wang's academic circle came either from the West or Japan.

Here I want to introduce the fourth definition of guoxue. Guoxue as academic learning, which attempted to internally explain Chinese culture, was determined to distinguish itself from external "Sinology" and later "Chinese studies." Together they developed into the major components and schools of today's "China learning" (zhongxue). Because of the awareness of each other's existence, neither guoxue nor Sinology could manipulate the knowledge and discourse on China.

However, this situation of co-existence also brings a potential danger to general China studies. Although guoxue and Sinology point to a common subject matter, their discourses define their respective boundaries and limitations, and at the same time question and deconstruct their opponent's expertise. From an epistemological perspective, any affirmative statement on China becomes invalidated. Under this situation, what is important for us is not to focus on how they disagree with each other on specific historical details, but to realise from a perspective of knowledge production that they could never achieve coherent ideas about China due to their differences in research agenda, thinking habits, problematics, and academic tradition.

Consequently, in the constant dialogue between guoxue and Sinology, Chineseness was defined as elastic and changeable. While I am presiding over the largest translation project of Sinology in the Chinese-speaking world, my daily work has to attend to how to achieve a precarious balance between guoxue and Sinology. On the one hand, I admonish intellectual closed-mindedness by arguing, "To prevent the senescence and rigidity of our mind, we will have to open our eyes to all academic studies on China (including Sinology) in order to embrace a changing and vital conception of China." (40)

At the same time, I must point out that if we blindly followed "Sinology" and complied with its hegemonic discourses, we would catastrophically lose our intellectual initiative and misrepresent Chinese experience, which would lead to academic blindness and aphasia. As I point out from one of my articles, "Sinology is a branch of both Chinese learning and Western learning. In comparison to indigenous guoxue, it belongs to a different discourse system. Even though Chinese tradition has already been tested by drastic Western influences, this large-scale introduction of systematic Sinology will create a new round of crisis by testing or even destroying the self-determination of the Chinese community and shaking the last foundation of our identity." (41)

More significantly, the dominant trend of "China learning" in the world has now shifted from European and Japanese "Sinology" to American "Chinese studies." Currently, the penetration of "Sinology" into indigenous guoxue has created a much more pressing sense of alienation than in Wang Guowei's time. Even though some American scholars of China have emphasised the "China-centred" approach, ${ }^{(42)}$ the more effort they make to "enter Chinese learning," the more "advanced" and "Europeanised" theories they have to rely on. This only shows that "sinology" is fundamentally a branch of "Western learning."

Under these circumstances, if we still agree that the richness of Chinese spirit comes from Chinese philosophers' "golden mean," and if we still re-

37. Qian Mu, Preface to Zhongguo xueshu tongyi (Survey of Chinese learning), Taipei, Xuesheng shuju, 1975, p. 5.

38. Lu Maode, "Lun guoxue de zhengtong" (On the orthodoxy of national learning), Zeshan (Inquiring goodness), vol. 2, no. 22, February 1942.

39. Ma Yifu, "Lun zhi guoxue xian xu bianming sidian" (To clarify four points prior to doing national learning), in Ma Yifu, Taihe Yifu ji, op. cit., p. 9.

40. Liu Dong, "Xu yuedu zhongguo congshu" (Preface to the Series of Reading China), in Liu Dong, Yong shu pu cheng de lu (The road paved by books), Beijing, Beijing daxue chubanshe, 2010, p. 113.

41. Ibid.

42. See Paul A. Cohen, Discovering History in China: American Historical Writing on the Recent Chinese Past, New York, Columbia University Publishing Press, 1984. 
member that Liang Qichao aspired to the compromise and balance "between tradition and modernity, preservation and renovation, enlightenment and transformation, Rujia and freedom, Chinese learning and Western learning, and even Chinese learning and Japanese learning," the existence of Sinology will fundamentally challenge our presumptions and motives of academic practice. By suggesting an imaginative boundary to guoxue, the existence of external "China learning" provides an external perspective to contrast with guoxue's internal perspective on the same subject matter - China. As I have argued in another article, "If Sinology is external, guoxue is introspective. If Sinology is value-free, guoxue is sympathetic. If Sinology is calm or dispassionate, guoxue is compassionate. If Sinology is experimental or anatomic, guoxue is devotional." " ${ }^{43)}$ To maintain a balanced attitude toward China studies, we must expand our vision and never reject any convincing reasons, even if these reasons are offered by our opponents. However, we must also respect our own experiences and mind and never blindly follow external authority, even at the risk of losing the cheap "international reputation." Then we can develop guoxue as a totality of Chinese culture. Through its dialogue with "Sinology," guoxue thus can be both modern and Chinese, global and indigenous, open and independent. From neo-Confucianism to modern literati painting, (44) from Mei Lanfang's reform of Peking Opera to Yuan Xuefen's reinvention of Yueju Opera, (45) these successful practices demonstrate that my idea is not only a theoretical prospect, but also a practical solution.

\section{Guoxue as the foundation of indigenous value in the age of globalisation}

As I mention earlier in this article, the practice that used the nation-state to narrowly designate "learning and culture" was not even accepted by scholars such as Qian Mu and Ma Yifu who identified themselves strongly with Chinese culture, not to mention those harshly critical of it. For instance, when He Bingsong explored the reasons Chinese learning was designated by the nation-state, he observed, "We know Germany makes great contributions to science and history, France to literature and philosophy, United States to social sciences, England to literature, economics, and political science, and Japan to historical geography. However, none of them has 'guoxue.' If we have something called guoxue, I want to know its characteristics, values, and contributions to world learning." (46) In fact, at that time it was no accident that all these countries without guoxue were also the great powers in the world. In great confidence, they expected their culture to be "advanced" and universal. For the purpose of national expansion, it was thus not desirable to designate a national boundary to constrain their culture. In contrast, countries that used the nation-state to designate their culture often faced a pressing mission to transform spatial confrontations between civilisations into temporal conflicts between "tradition and modernity" for the purpose of the preservation of cultural territory in the face of destructive invasion from the West.

This question suggests a fifth perspective on guoxue. In the contemporary world dominated by the two competing forces of "globalisation" and "post-colonialism," every cultural tradition, no matter how archaic, is forced to take up the form defined by the nation-state in order to obtain attention and recognition. From a global perspective, the production of guoxue or the "learning of the nation-state" (minzu guojia zhixue) belonged to a general trend in the non-Western world. In other words, the
non-Western nation-states would create as many guoxues as possible in order to resist the challenges posed by Western learning.

In fact, from the Japanese movement to overcome modernity, to Russian Slavism, and to Gandhism in India, these movements were various responses to the invasion of Western culture. Similar to Chinese neo-Confucianism, they belonged to each nation-state's respective guoxue. From a historical perspective, through creative transformation, the different kinds of guoxues not only managed to maintain their distinctive national characteristics and cultural identity but also constructed a collective defence line through dialogue with Western civilisation. In this sense, Chinese guoxue is not only historically significant, but also practical and indispensable for the contemporary world.

Early in 1927, Yang Honglie, a graduate of the Tsinghua Academy of Chinese Learning, already perceived indigenous culture from a global perspective. According to Yang, "Guoxue belongs to one of the five cultures in the world. Greek civilisation, Hebrew culture, Mohammedan civilisation, and Indian civilisation are all dead now. In the contemporary world, only China preserves world culture." (47) In 1935, from a perspective of comparative culture, Huang Yimin emphasised guoxue as the foundation to establish the Chinese nation-state: "All the nations in the world that establish their state require support from their spiritual achievements. It is spiritual civilisation that distinguishes each country... Only this unique national spirit can promote a nation's development. The so-called guoxue, Sinology, is this kind of angel." (48) After one hundred years, we still believe in this idea, even though we may express it differently.

From this new angle, guoxue has different implications. When compared with Sinology, guoxue is just a "regional study" within "Western learning" that corresponds to self-consciousness of Chinese national culture. However, when guoxue is understood from a global perspective, it is not a specific branch of "Western learning" any more, but speaks to the entire system of "Western learning." In other words, when achieving the same status as "Western learning" in terms of its value system, Chinese guoxue will not compete with Western learning on the margins but is engaged in what Max Weber has called "the war of gods," which is concentrated on the question of value rationality.

In this framework, guoxue is a defence and advocacy of diversity of choice and richness of thinking in its insistence on the particularity of Chinese culture. However, guoxue should not focus only on particularity, but also needs to demonstrate its concern for commonality and universality, particularly on philosophical questions regarding human life. In this sense, rather than just serving as "regional knowledge" to provide a dispensable supplement to a universal Western culture, guoxue should emphasise its distinctive goal, which is, recalling Chen Yinque, "to use my knowledge to reveal Providence" (wu ji suo xue guan tianyi) and provide an answer with Chinese characteristics to this question while rejecting a universal solution offered by the Western formula.

43. Liu Dong, "Qinghua guoxue yu yuwai hanxue" (National learning in Tsinghua and foreign Sinology), in Liu Dong, Daoshu yu tianxia, op. cit., p. 324

44. See Wan Qingli, Bingfei shuailuo de bainian (Not a declined century), Guiyin, Guangxi shifan daxue chubanshe, 2008.

45. See He Tian, "Bijiao shiye zhong de yueju wenhua" (Culture of Yueju Opera from a comparative perspective), PhD dissertation, Beijing University, 2009.

46. He Bingsong,"Lun suowei guoxue," op. cit.

47. Yang Honglie, "Guoxue zai shijie wenhua de weizhi" (The position of national learning in the world culture), Nankan daxue zhoubao, no. 44 and 45, 16 and 30 November 1927.

48. Huang Yimin, Preface to Guoxue conglun (A Series of National Learning), Beijing, Beiping yanyou xueshe, 1935, p. 1. 
In recent decades, in fact, Western philosophers such as Herbert Fingarette and David Hall began to understand Chinese culture from the perspective of Chinese values. ${ }^{\left({ }^{49}\right)}$ Along with the increasing influence of China and the popularity of Chinese language, leading international philosophers such as Alasdair Maclntyre and Charles Taylor also have taken the initiative to converse with their Chinese colleagues. ${ }^{(50)}$

Only this kind of "dialogue with the other" (dui zhe jiang) can elaborate guoxue's meaning for humanity in its appeal to a higher standard of global culture. In contrast to the "dialogue with tradition" (jie zhe jiang), which assumes the continuity and priority of tradition and embraces an essentialist stance, "dialogue with the other" can launch cultural construction without predefined cultural tendency and identity. In doing so, "dialogue with the other" can overcome cultural determinism and offer more intellectual choice through "intercultural dialogue." (51)

"Dialogue with the other" also refers to the deployment of an ethical and aesthetic attitude to rethinking our increasingly Westernised modern life. In this sense, guoxue does not "dig into old papers" (zuan guzhi dui), but requires passionate reflection on contemporary life, through which it can be constantly rejuvenated.

\section{Constructing an active subjectivity based on interculturality}

In the process of "dialogue with the other," I believe that guoxue can generate a higher form of civilisation through a long period of transplantation and hybridisation, even though cultural clashes may be initially destructive and violent. Early in 1923, Hu Pu'an already confidently stated that "while some people believe that Chinese learning is going to perish soon, I think this is the opportunity for its revival. The interaction with some other learning can regenerate a new Chinese learning." (52)

Some people worry that the rise of traditional learning and culture will instigate the upsurge of nationalism. This incorrect judgment ignores the complexity and flexibility of colonised society, as Partha Chatterjee points out in his study of nationalism. ${ }^{(53)}$ Moreover, this view also overlooks nationalism's positive implications for minority groups. As Craig Calhoun points out, "[l]t is impossible not to belong to social groups, relations, or culture. The idea of individuals abstract enough to be able to choose all their 'identifications' is deeply misleading. Versions of this idea are, however, widespread in liberal cosmopolitanism. They reflect the attractive illusion of escaping from social determinations into a realm of greater freedom, and from cultural particularity into greater universalism." (54)

Moreover, those who worry about the contemporary fate of guoxue also lack this vision: in the process of cultural interpenetration and hybridisation, guoxue will regenerate itself as the cultural form of the post-nationstate by consulting contemporary life experience and absorbing the essences of foreign culture. Early in 1935, Wang Xinming and other professors already predicted guoxue's open attitude:

China-based cultural construction adopts a critical attitude and a scientific approach to investigating the past, grasping the present, and creating the future. This attitude is not conservative, but attempts to discard the dross and preserve the essence. This new culture does not blindly follow others, but absorbs the merits of other cultures and remove our own defects... In doing so, China can regain glory in the cultural area and will become a strong force to promote global harmony. ${ }^{(55)}$
During the history of China's communication with foreign countries, ancient Chinese once introduced another kind of "Western learning" (Indian Buddhism) into their own intellectual domain. After a period of assimilation, Buddhism was finally transformed into part of Chinese culture. To anticipate this kind of synthesis as the future of Chinese culture, Zhang Shuhuang in 1935 reiterated Zhang Zhidong's famous principle: "The amalgamation of Chinese and Western learning will create a new culture in ten years. Zhang Zhidong's idea of 'Chinese essence and Western function' will be realised in the future." (56) From a historical and academic perspective, this kind of cross-cultural desire not only demonstrates "Chinese tolerance" (zhongguo qipai) but also reveals its global vision. In the contemporary world, rather than rigidly focusing on the limitations of Zhang Zhidong's principle, we should instil new spirit and intellectual energy into this cultural creed and use it to guide our understanding of Chinese learning.

When China was forced to open its doors, Zhang Zhidong's idea of "Chinese essence and Western function" deployed a protective strategy in the sense offered by Imre Lakatos, ${ }^{(57)}$ which led to a simplistic dichotomy between "Western matter and Chinese spirit." However, this idea, no matter how inaccurate it was, suggested the possibility of an active experiment to select and evaluate Western learning.

In a complicated contemporary global context, no matter what we want to select from Western learning and no matter what "Western function" means for us, fundamentally speaking, we cannot throw away "Chinese essence." Without "Chinese essence" we will lose the core of our identity and the foundation of moral values. The consequence will be the demise of the Chinese culture.

However, this stance does not prevent us from recognising the fact that the initial understanding of "Chinese essence" or "the subjectivity of Chinese civilisation" was very rudimentary. For instance, an article written in 1915 stated, "Science is the learning of materialism, but guoxue is the learning of mentalism. Guoxue is good at advocating national character and inspiring the mind... Science is good at investigating morality and examining matter... The two are closely associated with life and society and are not antagonistic." (58) Although this idea was still very simplistic, it already showed an enlightened and tolerant cultural stance. Unfortunately, these ideas, which aimed for a solid and firm foundation for societal transformation, were often misinterpreted as "monsters" based on the logic of cultural radicalism.

In the history of Chinese communication with Western civilisation, this drama of cultural clash was revealed in "passive resistance" (beidong

49. See Herbert Fingarette, Confucius: The Secular As Sacred, Long Grove, Waveland Press, 1998; David L. Hall and Roger T. Ames, Thinking through Confucius, Albany, State University of New York Press, 1987.

50. See Wan Junren, "Rujia meide lunli jiqi yu maijintaier zhi yalishiduode zhuyi de shicha" (The difference between Confucian ethics and MacIntyre's Aristotelianism), Zhongguo xueshu, no. 6, 2001.

51. Liu Dong, "Cong 'duizhejiang' dao 'jiezhejiang"' (From " dialogue with the Other" to " dialogue with tradition"), in Liu Dong, Daoshu yu tianxia, op. cit.

52. Hu Pu'an, "Minguo shi'ernian guoxue zhi qushi" (The trend of national learning in the twelve years after the establishment of the Republic), Minguo ribao, 10 October 1923.

53. See Partha Chatterjee, Nationalist Thought and the Colonial World: A Derivative Discourse, Minneapolis, University of Minnesota Press, 1993.

54. Craig Calhoun, "Is it Time to Be Postnational?", Zhongguo xueshu, no. 21, 2005, p. 25.

55. Wang Xinming, "Zhongguo benwei de wenhua jianshe xuanyan," op. cit.

56. Zhang Shuhuang, "Guoxue jinhou zhi qushi" (The trend of national learning in the future), Guoguang zazhi, no. 12, December 1935

57. See Imre Lakatos, The Methodology of Scientific Research Programmes, London, Cambridge University Press, 1980.

58. Xiao Gongbi, "Kexue guoxue bingzhong lun" (On the equal importance of science and national learning), Xuesheng zazhi 2, no. 4, April 1915. 
kangju) and "active pursuit" (zhudong zhuiqiu). On the one hand, in the history of modern China, cultural confusion and chaos often resulted from the forced introduction of the Hebrew spirit, particularly the introduction of Christianity. On the other hand, Chinese active pursuit of Greek heritage constituted the core of modern Chinese values, including "Mr. Democracy" and "Mr. Science," which served as rational ideals to criticise reality. For this reason, I want to propose a synthesis of Chinese and Greek civilisation.

The two ancient civilisations share a variety of key words such as multiplicity, secularity, sensibility, aesthetics, optimism, scepticism, the golden mean, rationality, debate, ethics, and so on and so forth. Historical contingencies (including geography) led to different paths of development, but the similarities offer possibilities for healthy and beneficial complementarity. For this reason, intellectual resources from Greek heritage attracted Chinese philosophers to welcome this close relative of Chinese civilisation as a means of developing spiritual and institutional genes. This is the key spirit of "Chinese essence and Western function."

In this sense, a reasonable principle of "Chinese essence and Western function" will recognise the fact that our cultural tradition contains valuable seeds of life philosophy. At the same time, "Chinese essence" also needs to debate and interact with foreign civilisations in order to fully reveal its advantages. As Zhang Dongsun pointed out in 1935, "We must first restore subjective (zhuti) integrity and then we can absorb other cultures. The subject emphasises the inner self... Without self-determination, a nation cannot adopt other civilisations, but will be conquered by them." (59) Therefore, "we should restore inherited Chinese culture while introducing Western culture." Zhang Dongsun continued, "The two are not antagonistic, but complementary... In many areas, such as politics and economy, it is necessary to adopt European methods. However, in terms of life philosophy, Chinese culture is most elaborate. We should preserve its essence." (60)

What is the prospect offered by "dialogue with others?" The process of global dialogue will not only bring about the development of national learning from different nations, but also result in a higher form of global civilisation. Global culture will develop out of continuous round-table discussion, which allows every culture to make special contributions by insisting on its particularity. Through a process of convergence and interaction, a network of multiple human cultures will be created out of interculturality and its internal tensions.

With this optimistic prediction, I will introduce the last perspective on guoxue. The multiplicity of guoxue from different nations offers the possibility both of violent confrontation and of co-existence of different civilisations. Dialogues between different guoxues can promote their respective virtues and overcome their limitations. This is the future for our global village.

\section{Six definitions of guoxue in the sense of linguistic embryology}

In consideration of the confusion of guoxue's meaning, this article has selected some of the most representative arguments about guoxue in order to produce a series of "embryological definitions" (fashengxing dingyi). While I do not naively believe that this historical investigation can bridge the gaps among guoxue's different definitions, I have attempted to show the multiple aspects of this "embryological process" through which different notions of guoxue may confront each other.
From a post-Wittgensteinian perspective, this article deploys a new notion of definition that understands everyday language as a series of shifting and changing regulations. In this sense, these definitions regard the multiple meanings of guoxue as the products of competition and interaction between the different interpretations of guoxue. Therefore, the concept of guoxue is not rigid, singular, and natural, but a compound consisting of a series of explanations that are internally heterogeneous and oppositional.

Based on their respective historical context and their specific point of view, the various discussions on guoxue thus project their specific references to their specific meaning. Along with changing conditions and subject matter, these meanings point to changing notions of guoxue.

This article has organised different notions of guoxue from the late Qing to Republican China into a Hegelian type of narrative that gives priority to logical sequence over historical chronology. For this reason, although I try to let the historical materials speak to a specific aspect of guoxue, these meanings of guoxue have been filtered through my own understanding of this subject matter.

Although objectivity is not the goal of my work here, I still hope this article will at least achieve two consensuses. First, from the great quantity of materials I cite in this article, we discover that some of the thoughtful arguments of contemporary scholars were already pointed out by earlier scholars. While we deeply appreciate this continuity of thinking, we also regret that we could not avoid the admonitions of these pioneers. Second, although many arguments now seem extreme, they are still worthy of our attention, because each argument keenly catches one reasonable aspect of the problems of guoxue. For this reason, it is their continuous rethinking of these problems that creates a higher intellectual platform. In many cases, we cannot even trace the identities behind the names who offered those thoughtful ideas. This article is thus dedicated to these modern scholars who insisted on freedom of thought by pursuing the true meaning of guoxue.

\section{Edited and translated from the Chinese by Guannan Li}

